\title{
STUDI PERBANDINGAN VARIASI ARUS TERHADAP KEKUATAN TARIK DAN STRUKTUR MIKRO BAJA AISI P20 DENGAN METODE PENGELASAN SMAW (SHIELDED METAL ARC WELDING)
}

\author{
Muhammad Yusuf ${ }^{1} *$ Mahadi $^{2}$ \\ Departemen Teknik Mesin, Fakultas Teknik, Universitas Sumatera Utara \\ mhdysuf@gmail.com
}

\begin{abstract}
ASTRACT
Determination of the amount of welding current for the joining of metals in electric arc welding will affect the quality of the welding joint In this research using AISI P20 medium carbon steel with welding method Shield Metal Arc welding (SMAW), welding current 80 $\mathrm{A}, 100 \mathrm{~A}$ and $120 \mathrm{~A}$, as well as electrode type E6013 diameter $3.2 \mathrm{~mm}$. The purpose of this research is to determine the influence of the variation in the welding current to the tensile strength and micro photo on AISI P20 steel. The concept of this research is to test the tensile strength on AISI P20 steel welding. In this study, AISI P20 steel was welded using a $V$ groove and a horizontal or underhand welding position. The results of this research at 80 A welding current obtained an average tensile strength of $426.757 \mathrm{~N} / \mathrm{mm} 2$, an average strain of $1.59 \%$ and an average modulus of elasticity of $29370.97 \mathrm{~N} / \mathrm{mm} 2$. At 100 A current has an average tensile strength value of 533,664 $\mathrm{N} / \mathrm{mm} 2$, an average strain of $3.28 \%$ and an average modulus of elasticity of $17017.49 \mathrm{~N} / \mathrm{mm} 2$. At a current of $120 \mathrm{~A}$, the average tensile strength value is $616,678 \mathrm{~N} / \mathrm{mm} 2$, the average strain is $4.52 \%$ and the average modulus of elasticity is $13791.04 \mathrm{~N} / \mathrm{mm} 2$. Overall, the tensile strength resulting from AISI P20 steel welding with a current variation of $80 \mathrm{~A}, 100 \mathrm{~A}$ and $120 \mathrm{~A}$ has decreased from the strength of the steel without welding, which is $616,678 \mathrm{~N} / \mathrm{mm} 2$ (the highest tensile strength test results) and $784.8 \mathrm{~N} / \mathrm{mm} 2$ (without welding). The results of microphotos show the finer details and reduced porosity in the weld area due to an increase in welding current variations.
\end{abstract}

Keywords: Shield Metal Arc Welding (SMAW), current variations, AISI P20 steel, E6013 electrode, tensile test

\begin{abstract}
ABSTRAK
Penentuan besarnya arus pengelasan untuk penyambungan logam pada las busur listrik akan mempengaruhi kualitas hasil sambungan las. Pada penelitian ini menggunakan baja karbon menengah dengan metode pengelasan Shield Metal Arc Welding (SMAW), arus pengelasan $80 \mathrm{~A}, 100 \mathrm{~A}$ dan $120 \mathrm{~A}$, serta jenis elektroda E6013 diameter 3,2 mm. Tujuan dilakukannya penelitian ini adalah untuk mengetahui pengaruh variasi arus pengelasan terhadap kekuatan tarik dan foto mikro pada baja AISI P20. Konsep penelitian ini adalah dengan menguji kekuatan tarik pada pengelasan baja AISI P20. Pada penelitian ini, baja AISI P20 dilas dengan menggunakan jenis kampuh $\mathrm{V}$ groove dan posisi pengelasan mendatar atau bawah tangan. Hasil dari penelitian ini pada arus pengelasan 80 A diperoleh kekuatan tarik rata - rata 426,757 N/mm2, regangan rata-rata sebesar 1,59 \% dan rata-rata nilai modulus elastisitasnya sebesar 29370,97 N/mm2. Pada arus 100 A memiliki nilai kekuatan tarik rata-rata sebesar 533,664 N/mm2, regangan rata-rata sebesar 3,28\% dan ratarata nilai modulus elastisitasnya sebesar 17017,49 N/mm2. Pada arus 120 A diperoleh nilai kekuatan tarik rata-rata sebesar 616,678 N/mm2, regangan rata-rata sebesar 4,52 \% dan rata-rata nilai modulus elastisitasnya sebesar 13791,04 N/mm2. Secara keseluruhan, kekuatan tarik yang dihasilkan dari pengelasan baja AISI P20 dengan variasi arus $80 \mathrm{~A}$, 100 A, dan 120 A mengalami penurunan dari kekuatan baja tanpa lasnya yaitu 616,678 $\mathrm{N} / \mathrm{mm} 2$ (kekuatan tarik hasil pengujian tertinggi) dan 784,8 N/mm2 (tanpa las). Adapun hasil foto mikro menunjukkan butiran semakin halus dan berkurangnya porositas pada daerah lasan diakibatkan peningkatan variasi arus pengelasan.
\end{abstract}

Kata kunci : Shield Metal Arc Welding (SMAW), Variasi Arus, Baja AISI P20, Elektroda E6013, Uji Tarik 


\section{PENDAHULUAN}

Teknologi pengelasan merupakan salah satu bagian yang tidak bisa dipisahkan dalam teknologi manufaktur. Ruang lingkup penggunaan teknologi pengelasan ini cakupannya meliputi rangka baja, perkapalan, jembatan, kereta api, pipa saluran dan lain sebagainya. Mutu dari pengelasan di samping tergantung dari pengerjaan lasnya sendiri dan juga sangat tergantung dari persiapan sebelum pelaksanaan pengelasan, karena pengelasan adalah proses penyambungan antara dua bagian logam atau lebih dengan menggunakan energi panas, secara umum pengelasan dapat diartikan sebagai suatu ikatan metalurgi pada sambungan logam atau logam paduan yang dilaksanakan saat logam dalam keadaan cair. Pada penelitian ini pengelasan yang digunakan adalah las SMAW.

Kekuatan hasil lasan dipengaruhi oleh tegangan busur, besar arus, kecepatan pengelasan, besarnya penembusan dan polaritas listrik. Penentuan besarnya arus dalam penyambungan logam menggunakan las busur mempengaruhi efisiensi pekerjaan dan bahan las. Untuk dapat mengetahui pengaruh hasil pengelasan las listrik dengan variasi arus yang digunakan pada Baja AISI P20 terhadap uji kekuatan tarik dari pengelasan maka perlu dilakukan pengujian terhadap benda uji hasil dari pengelasan.

\section{METODE}

\subsection{Prinsip Kerja}

Las SMAW menggunakan elektroda berselaput sebagai bahan tambah. Busur listrik yang terjadi diantara ujung elektroda dan bahan dasar akan mencairkan ujung elektroda dan sebagian bahan dasar. Selaput elektroda yang turut terbakar akan mencair dan menghasilkan gas yang melindungi ujung elektroda, kawah Ias, busur Iistrik dan daerah las di sekitar busur listrik terhadap pengaruh udara luar. Cairan selaput elektroda yang membeku akan menutupi permukaan las yang juga berfungsi sebagai pelindung terhadap pengaruh luar.

Logam induk dalam pengelasan ini mengalami pencairan akibat pemanasan dari busur listrik yang timbul antara ujung elektroda dan permukaan benda kerja. Busur listrik dibangkitkan dari suatu mesin las. Elektroda yang digunakan berupa kawat yang dibungkus pelindung berupa fluks. Elektroda ini selama pengelasan akan mengalami pencairan bersama dengan logam induk dan membeku bersama menjadi bagian kampuh las.

Proses pemindahan logam elektroda terjadi pada saat ujung elektroda mencair dan membentuk butir-butir yang terbawa arus busur listrik yang terjadi. Bila digunakan arus listrik besar maka butiran logam cair yang terbawa menjadi halus dan sebaliknya bila arus kecil maka butirannya menjadi besar. 
Pola pemindahan logam cair sangat mempengaruhi sifat mampu las dari logam.Logam mempunyai sifat mampu las yang tinggi bila pemindahan terjadi dengan butiran yang halus. Pola pemindahan cairan dipengaruhi oleh besar kecilnya arus dan komposisi dari bahan fluks yang digunakan. Bahan fluks yang digunakan untuk membungkus elektroda selama pengelasan mencair dan membentuk terak yang menutupi logam cair yang terkumpul di tempat sambungan dan bekerja sebagai penghalang oksidasi.

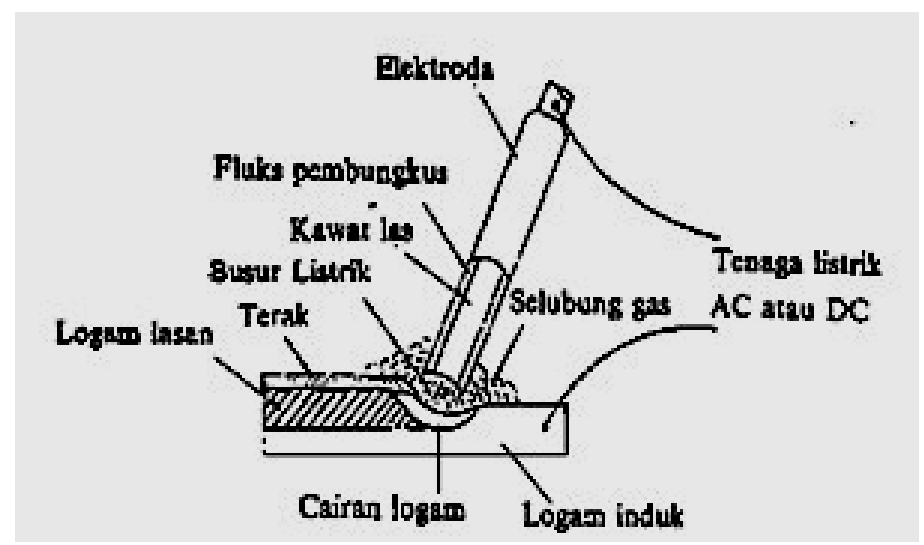

Gambar 2.1 Las SMAW (Wiryosumarto, 2004)

\subsection{Arus Pengelasan}

Pengelasan dengan kawat elektroda tunggal pada umumnya menggunakan tipe arus Direct Current (DC), elektroda positif (EP), jika menggunakan elektroda negatif (EN) penetrasi yang terbentuk akan rendah dan kuantiti las yang tinggi.

Tabel 2.1 Hubungan Diameter Elektroda Dengan Arus Pengelasan (Howard BC,1998)

\begin{tabular}{|c|c|}
\hline Diameter Elektroda (mm) & Arus (Ampere) \\
\hline 2,5 & $60-90$ \\
\hline 2,6 & $60-90$ \\
\hline 3,2 & $80-140$ \\
\hline 4,0 & $150-190$ \\
\hline 5,0 & $180-250$ \\
\hline & \\
\hline
\end{tabular}

\subsection{Baja AISI P20}

Baja AISI P20 merupakan jenis baja karbon sedang yang sangat penting untuk aplikasi berbagai kebutuhan dalam bidang teknik. Aplikasi baja paduan AISI P20 dalam bidang manufaktur bahan teknik, misalnya: heat exchenger, pipa boiler, serta sistem saluran pipa uap panas yang dapat digunakan pada pembangkit listrik panas bumi (PLTP) dan pembangkit listrik 
tenaga uap berbahan bakar batubara (PLTU). Berikut merupakan komposisi kima dari Baja AISI P20 yang dijabarkan pada Tabel 2.2

Tabel 2.2 Komposisi Kimia Baja AISI P20

\begin{tabular}{|l|l|}
\hline Unsur & $\%$ \\
\hline C & Max 0,360 \\
\hline Cr & 1,790 \\
\hline Mo & 1,180 \\
\hline Mn & Max 1,450 \\
\hline P & Max 0,007 \\
\hline S & Max 0,004 \\
\hline Si & Max 0.210 \\
\hline Fe & Sisa \\
\hline
\end{tabular}

\subsection{Pengujian Kekuatan Tarik}

Proses pengujian tarik bertujuan untuk mengetahui kekuatan tarik benda uji. Pembebanan tarik adalah pembebanan yang diberikan pada benda dengan memberikan gaya tarik berlawanan arah pada salah satu ujung benda. Penarikan gaya terhadap beban akan mengakibatkan terjadinya perubahan bentuk (deformasi) bahan tersebut. Proses terjadinya deformasi pada bahan uji adalah proses pergeseran butiran Kristal logam yang mengakibatkan melemahnya gaya elektromagnetik setiap atom logam hingga terlepas ikatan tersebut oleh penarikan gaya maksimum.

Berikut ini adalah gambaran singkat proses uji tarik dan datanya.
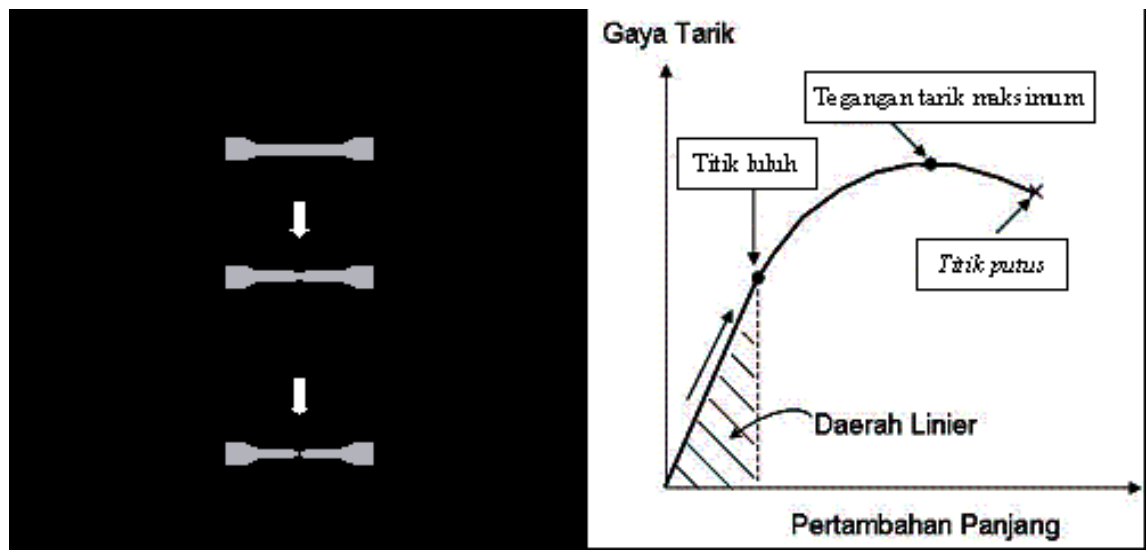

Gambar 2.2 Gambaran Singkat Uji Tarik Dan Datanya 


\section{HASIL DAN PEMBAHASAN}

\subsection{Hasil Uji Tarik}

Penelitian ini menggunakan jenis elektroda E6013 dengan variasi arus sebesar $80 \mathrm{~A}$, 100 A dan 120 A. Hasil pengujian tarik masing-masing variasi dapat dilihat pada Tabel 3.1, 3.2 dan 3.3

\subsubsection{Hasil Uji Tarik Pada Arus 80 A}

Tabel 3.1 Hasil Pengujian Tarik pada arus 80 A

\begin{tabular}{|l|r|l|r|r|r|r|}
\hline \multirow{2}{*}{ Arus } & L0(mm) & $\begin{array}{r}\text { Dimensi } \\
(\mathrm{mm})\end{array}$ & $\mathrm{L} 1(\mathrm{~mm})$ & $\mathrm{A}(\mathrm{mm} 2)$ & $\begin{array}{l}\text { Maximum } \\
\text { Force }(\mathrm{kgf})\end{array}$ & $\begin{array}{l}\text { Maximum } \\
\text { Stress } \\
(\mathrm{kgf} / \mathrm{mm} 2)\end{array}$ \\
\hline & 50 & $12,5 \times 9$ & 51.15 & 112.5 & 5420 & 48.18 \\
\cline { 2 - 7 } $80 \mathrm{~A}$ & 50 & $12,5 \times 9$ & 50.61 & 112.5 & 4750 & 42.22 \\
\cline { 2 - 7 } & 50 & $12,5 \times 9$ & 50.95 & 112.5 & 5100 & 45.33 \\
\cline { 2 - 7 } & 50 & $12,5 \times 9$ & 50.83 & 112.5 & 4980 & 44.27 \\
\cline { 2 - 7 } & 50 & $12,5 \times 9$ & 50.43 & 112.5 & 4220 & 37.51 \\
\hline
\end{tabular}

\subsubsection{Hasil Uji Tarik Pada Arus 100 A}

Tabel 3.2 Hasil Pengujian Tarik arus 100 A

\begin{tabular}{|l|r|l|r|r|r|r|}
\hline \multirow{2}{*}{ Arus } & L0(mm) & $\begin{array}{r}\text { Dimensi } \\
(\mathrm{mm})\end{array}$ & $\mathrm{L} 1(\mathrm{~mm})$ & $\mathrm{A}(\mathrm{mm} 2)$ & $\begin{array}{l}\text { Maximum } \\
\text { Force }(\mathrm{kgf})\end{array}$ & $\begin{array}{l}\text { Maximum } \\
\text { Stress } \\
(\mathrm{kgf} / \mathrm{mm} 2)\end{array}$ \\
\hline & 50 & $12,5 \times 9$ & 51.95 & 112.5 & 6620 & 58.84 \\
\cline { 2 - 7 } 100 A & 50 & $12,5 \times 9$ & 51.05 & 112.5 & 5240 & 46.58 \\
\cline { 2 - 7 } & 50 & $12,5 \times 9$ & 51.25 & 112.5 & 5560 & 49.42 \\
\cline { 2 - 7 } & 50 & $12,5 \times 9$ & 51.84 & 112.5 & 6480 & 57.60 \\
\cline { 2 - 7 } & 50 & $12,5 \times 9$ & 52.12 & 112.5 & 6700 & 59.56 \\
\hline
\end{tabular}

\subsubsection{Hasil Uji Tarik Pada Arus 120 A}

Tabel 3.3 Hasil Pengujian Tarik pada arus 120 A

\begin{tabular}{|l|r|l|r|r|r|r|}
\hline \multirow{2}{*}{ Arus } & L0(mm) & $\begin{array}{r}\text { Dimensi } \\
(\mathrm{mm})\end{array}$ & $\mathrm{L} 1(\mathrm{~mm})$ & $\mathrm{A}(\mathrm{mm} 2)$ & $\begin{array}{l}\text { Maximum } \\
\text { Force }(\mathrm{kgf})\end{array}$ & $\begin{array}{l}\text { Maximum } \\
\text { Stress } \\
(\mathrm{kgf} / \mathrm{mm} 2)\end{array}$ \\
\hline & 50 & $12,5 \mathrm{x} 9$ & 51.75 & 112.5 & 6550 & 58.22 \\
\cline { 2 - 7 } 120 A & 50 & $12,5 \mathrm{x} 9$ & 52.42 & 112.5 & 7260 & 64.53 \\
\cline { 2 - 7 } & 50 & $12,5 \mathrm{x} 9$ & 52.53 & 112.5 & 7550 & 67.11 \\
\cline { 2 - 7 } & 50 & $12,5 \mathrm{x} 9$ & 52.23 & 112.5 & 6840 & 60.80 \\
\cline { 2 - 7 } & 50 & $12,5 \mathrm{x} 9$ & 52.37 & 112.5 & 7160 & 63.64 \\
\hline
\end{tabular}


Tabel 3.4 Nilai Tegangan Tiap Spesimen

\begin{tabular}{|c|c|c|c|c|}
\hline $\begin{array}{c}\text { Jenis } \\
\text { Elektroda }\end{array}$ & $\begin{array}{c}\text { Kuat } \\
\text { Arus (A) }\end{array}$ & $\begin{array}{l}\text { Nomor } \\
\text { Spesimen }\end{array}$ & $\begin{array}{l}\text { Tegangan } \\
(\mathrm{N} / \mathrm{mm} 2)\end{array}$ & $\begin{array}{l}\text { Tegangan } \\
\text { Rata-rata } \\
(\mathrm{N} / \mathrm{mm} 2)\end{array}$ \\
\hline \multirow{15}{*}{ E6013 } & \multirow{5}{*}{80} & IA & 472.624 & \multirow{5}{*}{426.757} \\
\hline & & IIA & 414.2 & \\
\hline & & IIIA & 444.72 & \\
\hline & & IVA & 434.256 & \\
\hline & & VA & 367.984 & \\
\hline & \multirow{5}{*}{100} & IB & 577.264 & \multirow{5}{*}{533.664} \\
\hline & & IIB & 456.928 & \\
\hline & & IIIB & 484.832 & \\
\hline & & IVB & 565.056 & \\
\hline & & VB & 584.24 & \\
\hline & \multirow{5}{*}{120} & IC & 571.16 & \multirow{5}{*}{616.678} \\
\hline & & IIC & 633.072 & \\
\hline & & IIIC & 658.36 & \\
\hline & & IVC & 596.448 & \\
\hline & & $\mathrm{VC}$ & 624.352 & \\
\hline
\end{tabular}

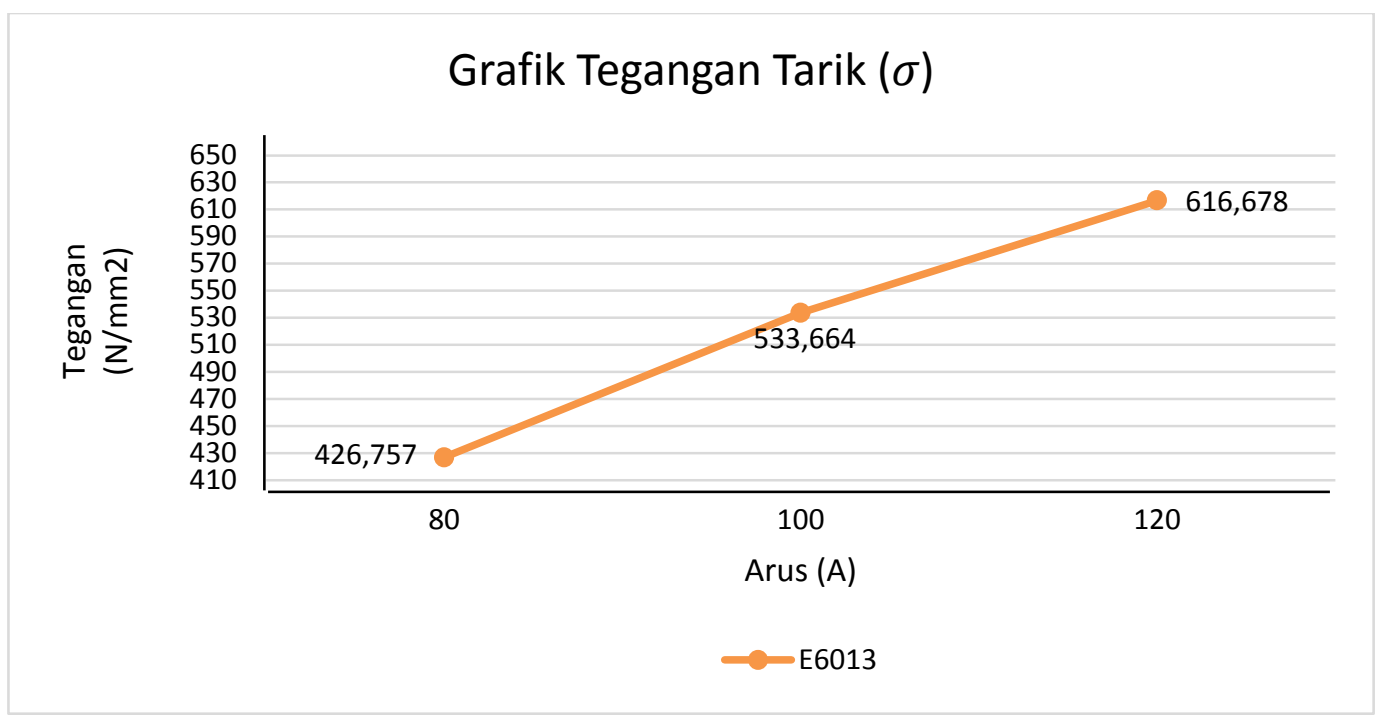

Gambar 3.1 Grafik Tegangan Tarik

Dapat dilihat dari gambar 3.1 bahwa baja AISI P20 elektroda E6013 diameter 3,2 mm dengan arus pengelasan 120 A memiliki nilai tegangan rata-rata tertinggi yaitu sebesar 616,678 $\mathrm{N} / \mathrm{mm} 2$. Sedangkan nilai tegangan rata-rata terendah yaitu dengan arus pengelasan 80 A sebesar 426,757 N/mm2. Hal ini menunjukkan adanya pengaruh kuat arus terhadap pengelasan baja AISI P20 untuk uji tarik. Dari grafik di atas di dapat bahwa semakin besar kuat arus pengelasan yang digunakan maka tegangan rata - rata akan semakin naik. 


\section{KESIMPULAN}

Kekuatan tarik hasil las baja AISI P20 menggunakan elektroda E6013 dengan arus 80 A memiliki nilai kekuatan tarik rata-rata sebesar $426.757 \mathrm{~N} / \mathrm{mm} 2$, regangan rata-rata sebesar 1.59 \% dan rata-rata nilai modulus elastisitasnya sebesar $29370.97 \mathrm{~N} / \mathrm{mm} 2$. Pada arus $100 \mathrm{~A}$ memiliki nilai kekuatan tarik rata-rata sebesar $533.664 \mathrm{~N} / \mathrm{mm} 2$, regangan rata-rata sebesar $3.28 \%$ dan rata-rata nilai modulus elastisitasnya sebesar $17017.49 \mathrm{~N} / \mathrm{mm} 2$. Pada arus $120 \mathrm{~A}$ memiliki nilai kekuatan tarik rata-rata sebesar $616.678 \mathrm{~N} / \mathrm{mm} 2$, regangan rata-rata sebesar 4.52 $\%$ dan rata-rata nilai modulus elastisitasnya sebesar 13791.04 N/mm2.

Secara keseluruhan, kekuatan tarik yang dihasilkan dari pengelasan baja AISI P20 dengan variasi arus mengalami penurunan dari kekuatan baja tanpa lasnya yaitu sebesar 616.678 $\mathrm{N} / \mathrm{mm} 2$ (kekuatan tarik hasil pengujian teringgi) dan 784,8 N/mm2 (tanpa las).

\section{REFERENSI}

[1] Alip, M. 1989. Teori dan Praktik Las. Jakarta: Departemen Pendidikan dan Kebudayaan.

[2] Surdia, T. \& Saito, S. 1999. Pengetahuan Bahan Teknik. Jakarta: Pradnya Paramita Cetakan ke IV.

[3] Wiryosumarto, H. \& Okumura, T. 2004. Teknologi Pengelasan Logam. Jakarta : Pradnya Paramita Cetakan ke VIII. 